\title{
PROPUESTA DE UNA PEQUEÑA PLANTA DE TRATAMIENTO DE AGUA POTABLE EN EL MEDIO RURAL DE TACNA
}

\author{
Responsable: Ing ${ }^{\circ}$ Edgar Chura Arocutipa
} Miembro: Ing ${ }^{\circ}$ Raúl Ardiles Flores

\section{RESUMEN}

En la región Tacna, en el medio rural del valle de Tacna, distritos de Calana, Pachía e irrigación Magollo, el riego de parcelas de cultivo es con aguas superficiales provenientes del canal Caplina y del Uchusuma. El poblador rural se abastece de agua para el consumo de fuentes superficiales (canal de regadío), almacenado los dias que les toca el turno de riego. El agua solamente tiene un proceso de decantación.

Con el objetivo de contribuir a mejorar la salud y calidad de vida del poblador rural, se propone el diseño de una pequeña planta de tratamiento de agua potable en el medio rural de Tacna. Para su diseño, por las características similares de la zona, se ha considerado un módulo típico, para el servicio y uso de una familia rural compuesto de diez personas. La dotación requerido para su tratamiento es de $1,50 \mathrm{l} / \mathrm{s}$, la capacidad de almacenamiento es de $15 \mathrm{~m}^{3}$, que permitirá abastecer para un periodo de ocho dias. Las instalaciones de la planta de tratamiento están conformadas por un desarenador, floculador, sedimentador, filtro y reservorio de almacenamiento.

\section{INTRODUCCIÓN}

La población rural del Perú, según el INEI (2003), es de: 8.9 millones de habitantes (35\% de la población total), siendo su principal característica la pobreza, un $60 \%$ en condición de pobreza y un $24 \%$ en pobreza extrema. De los 8.9 millones de habitantes rurales, 3.3 millones no tienen acceso de agua potable, esto es de $37 \%$; y 6.2 millones carecen de una adecuada eliminación de excretas y aguas residuales, representa el $70 \%$.

El poblador rural del valle de Tacna, distritos de Calana, Pachía e irrigación Magollo se abastece de agua para su consumo de fuentes superficiales de los canales Caplina y Uchusuma, almacenando los días que les toca el turno de riego. El agua solamente tiene un proceso de decantación. Esta situación origina en el poblador rural riesgos en su salud como son las enfermedades gastrointestinales. Por los antecedentes mencionados, requiere ser estudiada la potabilización del agua en la zona rural de Tacna, aplicando las tecnologías apropiadas de tratamiento.

\section{OBJETIVOS}

1. Contribuir a mejorar la salud y calidad de vida de la población rural del valle de Tacna, mediante la propuesta de diseño de una pequeña planta de tratamiento de agua potable.

2. Proporcionar en el diseño y construcción un fácil manejo del proceso de potabilización del agua.

3. Proporcionar en el diseño el uso de materiales de construcción de la zona a bajo costo, y al alcance del poblador rural.

\section{UBICACIÓN DE LAZONADE ESTUDIO}

La zona de estudio se ubica en el valle de Tacna, distritos de Pachía, Calana y en la parte baja de la ciudad de Tacna como es la irrigación Magollo, cuya jurisdicción pertenece a la región de Tacna (ver Plano de Ubicación № 01).

\section{ANÁLISIS Y PROPUESTA DE DISEÑO}

Por los antecedentes indicados anteriormente, en el medio rural del valle de Tacna las tierras de cultivo están irrigadas con aguas superficiales del Caplina y del Uchusuma; consecuentemente, para el consumo humano estas aguas están contaminadas, máxime en épocas de verano cuando estás aguas llegan con alto contenido de arena, limo y basura, que constituye un alto grado de turbidez. El presente hecho ha motivado que se busque una alternativa de tratamiento de estas aguas superficiales y se pueda proponer un proceso de tratamiento que implique la potabilización de esta agua a bajo costo, con instalaciones fácilmente operables.

La dotación de agua para el riego es de 2,3 a 4 horas, según la extensión del fundo y para un periodo de riego aproximado de 5 a 7 días de intervalo.

Para el abastecimiento de consumo humano de estas fuentes, se considera tomando en cuenta el número de habitantes que viven en el fundo, con una dotación de $150 \mathrm{l} / \mathrm{hab} / \mathrm{dia}$, dado que en los meses de verano puede alcanzar mayores 
dotaciones por el calor y la higiene que normalmente debe tenerse.

Dentro de las alternativas de la planta de tratamiento seleccionado, el de tipo de tratamiento completo, si consideramos el aspecto operativo,es el que puede ser factible. El almacenamiento del agua cruda se efectuará sólo en unas cuantas horas ( 3 a 4), a intervalos de 7,5 a 8 dias ( cuando les toque su riego).

Para un módulo de vivienda rural conformado de 10 personas, con una dotación de 150 I/hab/día, el caudal requerido es de $1,50 \mathrm{l} / \mathrm{s}$, el volumen requerido para el abastecimiento es de $15 \mathrm{~m} 3$ que permitirá dotar al poblador para un periodo de 8 dias .

Las instalaciones de la planta de tratamiento, se han diseñado aplicando las tecnologias apropiadas para la zona y estarán constituidas de la siguiente forma (ver Esquema de Planta $N^{\circ} 02$ )

\section{- Desarenador:}

Estructura de forma rectangular de doble cámara, de dimensiones en planta de 1,00 x $4,00 \mathrm{~m}$ y profundidad de $0,50 \mathrm{~m}$.

- Tanque de Almacenamiento:

Estructura de forma rectangular de $3,00 \times$ $6,00 \mathrm{~m}$ y profundidad de $1,00 \mathrm{~m}$.

\section{- Floculador:}

De tipo de flujo horizontal de sección variable, mínimo de $0,20 \times 0,20 \mathrm{~m}$ y máximo de $3,00 \mathrm{x}$ $0,50 \mathrm{~m}$ longitud de $6,00 \mathrm{~m}$. En lugar de las pantallas se hará uso de piedras de río de $0,20 \mathrm{~m}$ de diámetro, acomodadas adecuadamente en el lecho de sección trapezoidal del floculador.

- Sedimentador:

Estructura de forma rectangular de $3,00 \mathrm{x}$ $5,00 \mathrm{~m}$ y profundidad de $0,50 \mathrm{~m}$.

- Filtros:

Estructura de sección de $0,70 \times 0,50 \mathrm{~m}$ y altura de $1,20 \mathrm{~m}$ conformado por una primera capa de arena de espesor de $0,30 \mathrm{~m}$ y segunda capa de grava de espesor de $0,30 \mathrm{~m}$ tamaño de $1 / 2$ " a $1^{\prime \prime}$.

\section{- Reservorio de Almacenamiento:}

El agua tratada se almacenará en un reservorio de capacidad de $15 \mathrm{~m} 3$, la estructura es de forma rectangular de dimensiones en planta de $4,00 \times 4,00 \mathrm{~m}$ y profundidad de $1,25 \mathrm{~m}$.

\section{CONCLUSIONES}

1. El poblador del valle de Tacna se abastece de agua para su consumo de fuentes superficiales provenientes del canal Caplina y el del Uchusuma. El agua solo tiene un proceso de decantación, no cuenta con un sistema de potabilización.

2. El tipo de planta de tratamiento propuesto, para un módulo de vivienda rural del valle de Tacna, está conformado por un desarenador, floculador,sedimentador,filtro y reservorio de almacenamiento. Se ha seleccionado esta alternativa por las condiciones de un tratamiento completo y puede ser operada por los pobladores de la zona, con la capacitación necesaria.

3. La dotación de agua para el consumo humano para un módulo rural conformado por 10 personas es de 1,5 l/s; para el proceso de su tratamiento requiere de un volumen de $15 \mathrm{~m} 3$, para un tiempo de almacenamiento de 8 dias.

4. Para el diseño y construcción de la planta de tratamiento se ha considerado la utilización de materiales de la zona, como agregados, piedra base y madera, permitiendo un menor costo en su construcción

\section{RECOMENDACIONES}

- Desarrollar programas de control y vigilancia para los cursos de agua superficiales, por las entidades competentes y grupos comunitarios, a fin de frenar el deterioro actual de la calidad del recurso hídrico.

- Capacitar al poblador rural en el manejo de la pequeña planta de tratamiento de agua y garantizar su operatividad y mantenimiento.

- Diseñar y ejecutar campañas educativas en la comunidad rural del valle de Tacna, relacionadas con la problemática de salud y el consumo de agua no potable.

- A través de la cooperación internacional, gestionar el financiamiento para la construcción de pequeñas plantas de tratamiento en el medio rural de Tacna.

\section{BIBLIOGRAFÍA}

Azevedo Netto y Acosta Álvarez Manual de Hidráulica, Ed. Harla-México, 1976

Andrew. L. Simón Hidráulica práctica, Ed. Limusa-México, 1986

Centro Panamericano de Ingeniería Sanitaria Tecnologia de tratamiento de agua, para países en desarrollo Ed. CEPIS, Lima, 1977.

Departamento de Sanidad del Estado de Nueva York Manual de tratamiento de aguas.

Ed. Limusa - México, 1987

Romero Rojas Jairo Potabilización del agua Ed. Alfaomega, Colombia, 1999. 


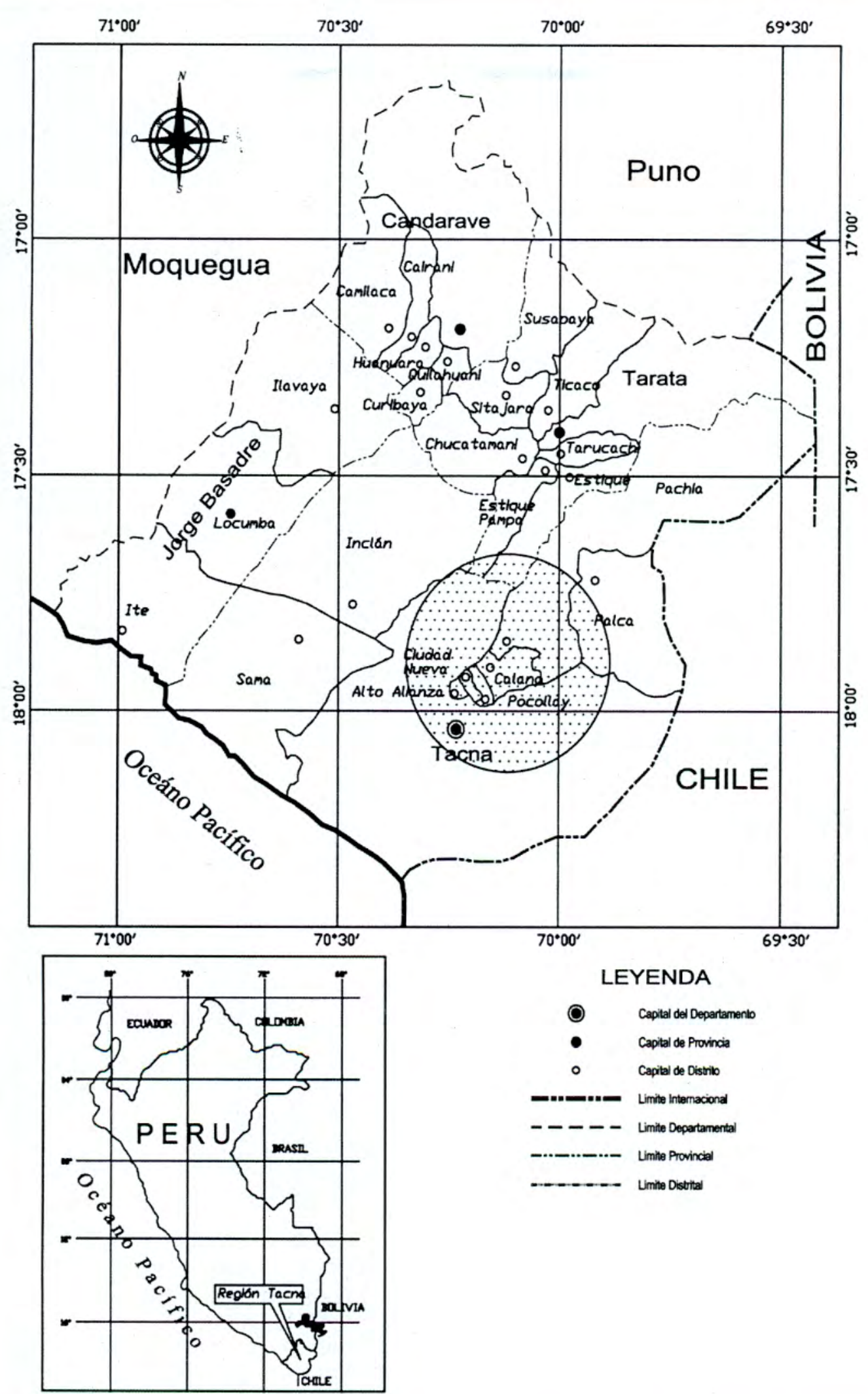

\begin{tabular}{|c|c|c|c|c|}
\hline \multicolumn{5}{|c|}{ PROTECTO IMVESTGACION } \\
\hline & \multicolumn{4}{|c|}{$\begin{array}{l}\text { PROPUESTA DE UNA PEQUEÑA PLANTA DE TRATAMIENTO } \\
\text { DE AGUA POTABLE EN EL MEDIO RURAL DE TACNA }\end{array}$} \\
\hline PUNO & \multicolumn{4}{|c|}{ UBICACION } \\
\hline $\begin{array}{l}\text { DSEAO } \\
\text { ECHA }\end{array}$ & $\begin{array}{l}\text { DiBwo } \\
\text { Tecnicado }\end{array}$ & $\begin{array}{l}\text { ESCAUA } \\
\text { INDICADA }\end{array}$ & $\begin{array}{l}\text { FECHA } \\
\text { DIC '05 }\end{array}$ & $\begin{array}{l}\text { PUWO } \\
01\end{array}$ \\
\hline
\end{tabular}



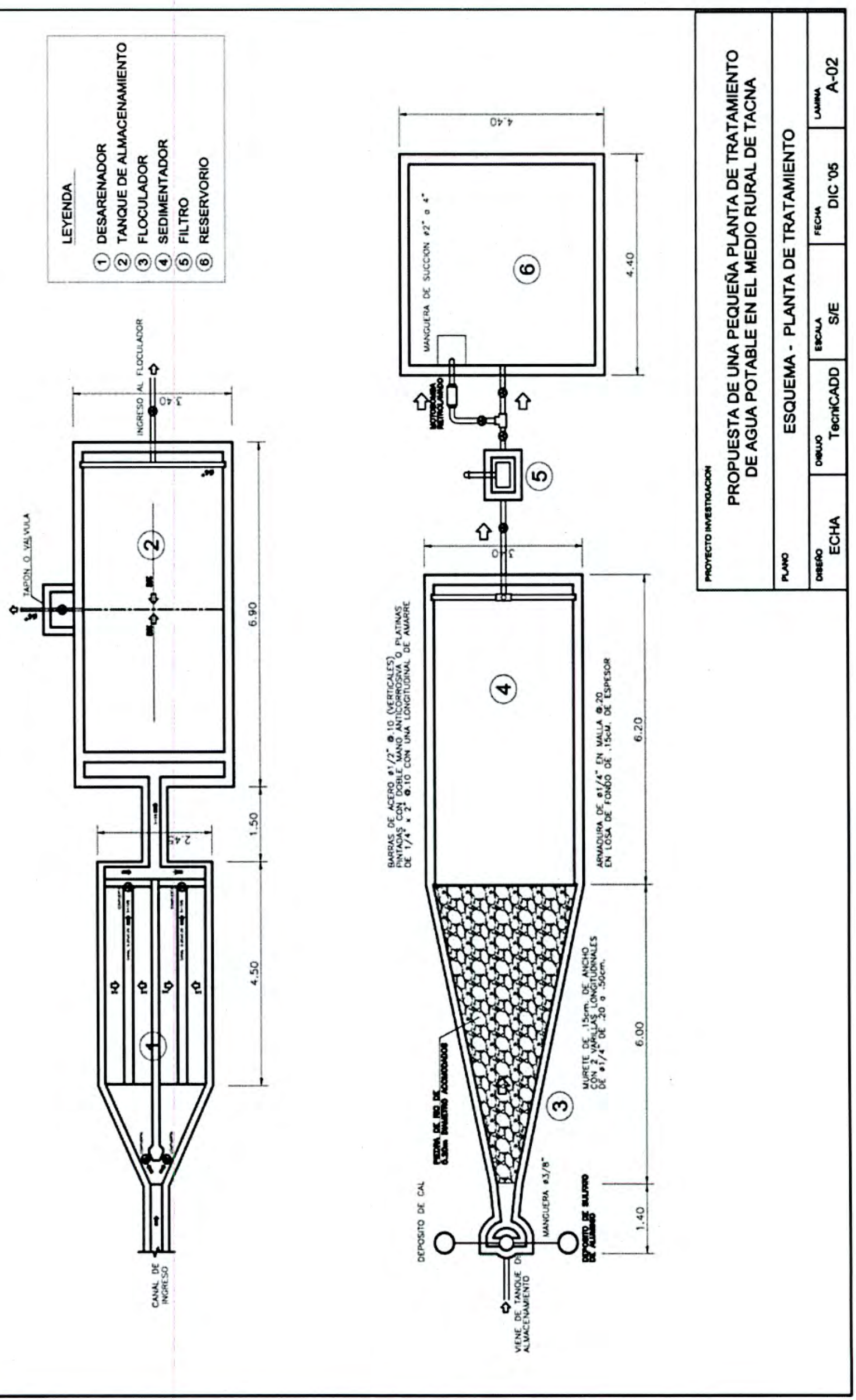